3 


\section{Progress in Probability}

\section{and Statistics}

Vol. 2

Edited by

P. Huber and

M. Rosenblatt

Springer Science+Business Media, LLC 


\section{Harry Kesten}

\section{Percolation Theory for Mathematicians}


Author:

Harry Kesten

Department of Mathematics

Corne 11 University

Ithaca, NY 14853

Library of Congress Cataloging in Publication Data

Kesten, Harry, 1937-

Percolation theory for mathematicians.

(Progress in probability and statistics; v. 2)

Bibliography: .

Includes index.

1. Percolation (Statistical physics) I. Title. II. Series.

QC174.85.P45K47 1982

ISBN 978-0-8176-3107-9

$530.1 ' 3$

$82-19746$

CIP-Kurztitelaufnahme der Deutschen Bibliothek

Kesten, Harry:

Percolation theory for mathematicians / Harry Kesten.

(Progress in probability and statistics; V01. 2)

ISBN 978-0-8176-3107-9

DOI $10.1007 / 978-1-4899-2730-9$

ISBN 978-1-4899-2730-9 (eBook)

NE: GT

All rights reserved. No part of this publication may be reproduced, stored in a retrieval system, or transmitted, in any form or by any means, electronic, mechanical, photocopying, recording or otherwise, without prior permission of the copyright owner.

(c) Springer Science+Business Media New York 1982

Originally published by Birkhäuser Boston, Inc. in 1982

ISBN 978-0-8176-3107-9 


\section{PREFACE}

Quite apart from the fact that percolation theory had its origin in an honest applied problem (see Hammersley and Welsh (1980)), it is a source of fascinating problems of the best kind a mathematician can wish for: problems which are easy to state with a minimum of preparation, but whose solutions are (apparently) difficult and require new methods. At the same time many of the problems are of interest to or proposed by statistical physicists and not dreamt up merely to demonstrate ingenuity.

Progress in the field has been slow. Relatively few results have been established rigorously, despite the rapidly growing literature with variations and extensions of the basic model, conjectures, plausibility arguments and results of simulations. It is my aim to treat here some basic results with rigorous proofs. This is in the first place a research monograph, but there are few prerequisites; one term of any standard graduate course in probability should be more than enough. Much of the material is quite recent or new, and many of the proofs are still clumsy. Especially the attempt to give proofs valid for as many graphs as possible led to more complications than expected. I hope that the Applications and Examples provide justification for going to this level of generality. I taught a graduate course on this material at Cornel1 University in Spring 1981, but the beginning of the monograph was a set of notes for a series of lectures at Kyoto University, Japan, which I visited in summer 1981 on a Fellowship of the Japan Society for the Promotion of Science.

I am indebted to a large number of people for helpful discussions. I especially value various suggestions made by J.T. Cox, R. Durrett, G.R. Grimmett and S. Kotani. I also wish to thank members of the Department of Mathematics at Kyoto University, and in particular my host, Professor S. Watanabe, for their hospitality and for giving me the opportunity to try out a first version of these notes in their seminar. Last but not least, I am grateful to the National Science 
Foundation and the Japan Society for the Promotion of Science for their financial support during my work on this monograph.

The reader should be aware of the fact that some standard notation is defined only in the Index of Symbols at the end.

Ithaca, New York, July 1982 


\section{TABLE OF CONTENTS}

1. Introduction and summary. 1

2. Which graphs do we consider? 10

2.1 Periodic graphs. 10

2.2 Matching pairs. 16

2.3 Planar modifications of matching pairs. 21

2.4 Separation theorems and related point-set topological results. 29

2.5 Covering graphs. 36

$\begin{array}{ll}2.6 & \text { Dual graphs. } \\ \text { Periodic percolation problems. } & 37\end{array}$

3. Periodic percolation problems. 40

3.1 Introduction of probability. Site vs bond problems. 40

3.2 Periodic site-percolation. $\quad 44$

3.3 Crossing probabilities and the principal theorem on percolative regions. 46

3.4 Critical probabilities. Applications of the principal theorems. 51

4. Increasing events. 69

4.1 The FKG inequality. $\quad 72$

4.2 Pivotal sites and Russo's formula. $\quad 74$

5. Bounds for the distribution of \#W. 81

5.1 Exponential fall off of $P\{\# W \geq n\}$. 83

5.2 Estimates above the percolation threshold. 97

5.3 Large crossing probabilities imply that percolation $\begin{array}{ll}\text { occurs. } & 121\end{array}$

6. The RSW Theorem. 126

7. Proofs of Theorems 3.1 and 3.2. 168

8. Power estimates. 198

9. The nature of the singularity at $\mathrm{p}_{\mathrm{H}}$. 238

10. Inequalities for critical probabilities. 255

10.1 Comparison of bond and site problems. 256

$\begin{array}{lll}10.2 & \text { Strict inequality for a graph and a subgraph. } & 261\end{array}$

10.3 Derivation of Condition E from Condition D. 295

11. Resistance of random electrical networks. 335

11.1 Bounds for resistances of networks. 335

11.2 Proof of Theorem 11.1. 343

11.3 Properties of resistances. 351

11.4 Proofs of Theorems 11.2 and 11.3. 371

12. Unsolved problems. 380 
Appendix .

386

References.

413

Author index.

418

Subject index.

419

Index of symbols.

421 